\title{
Targeting of a platinum-bound sunitinib analog to renal proximal tubular cells
}

This article was published in the following Dove Press journal:

International Journal of Nanomedicine

27 January 2012

Number of times this article has been viewed

\author{
ME (Emmy) M Dolman' \\ Stefan Harmsen' \\ Ebel HE Pieters' \\ RolfW Sparidans ${ }^{2}$ \\ Marie Lacombe ${ }^{3}$ \\ Bálint Szokol ${ }^{4}$ \\ László Őrfi ${ }^{4}$ \\ György Kéri ${ }^{4}$ \\ Gert Storm' \\ Wim E Hennink' \\ Robbert J Kok' \\ 'Department of Pharmaceutics, \\ Utrecht Institute for Pharmaceutical \\ Sciences, Utrecht University, \\ Utrecht, The Netherlands; ' $F$ Faculty \\ of Science, Department of \\ Pharmaceutical Sciences, Division of \\ Pharmacoepidemiology and Clinical \\ Pharmacology, Utrecht University, \\ Utrecht, The Netherlands; ${ }^{3}$ Kreatech \\ Biotechnology BV, Amsterdam, The \\ Netherlands; ${ }^{4}$ Vichem Chemie Ltd, \\ Budapest, Hungary
}

Background: Activated proximal tubular cells play an important role in renal fibrosis. We investigated whether sunitinib and a kidney-targeted conjugate of sunitinib were capable of attenuating fibrogenic events in tubulointerstitial fibrosis.

Methods: A kidney-targeted conjugate was prepared by linkage of a sunitinib analog (named 17864) via a platinum-based linker to the kidney-specific carrier lysozyme. Pharmacological activity of 17864-lysozyme was evaluated in human kidney proximal tubular cells (HK-2); the capability of the kidney-directed conjugate to accumulate in the kidneys was studied in mice. Potential antifibrotic effects of a single-dose treatment were evaluated in the unilateral ureteral obstruction (UUO) model in mice.

Results: The 17864-lysozyme conjugate and its metabolites strongly inhibited tyrosine kinase activity. Upon intravenous injection, 17864-lysozyme rapidly accumulated in the kidneys and provided sustained renal drug levels for up to 3 days after a single dose. Renal drug level area under the curve was increased 28 -fold versus an equimolar dose of sunitinib malate. Daily treatment of UUO mice with a high dose of sunitinib malate $(50 \mathrm{mg} / \mathrm{kg})$ resulted in antifibrotic responses, but also induced drug-related toxicity. A single dose of 17864-lysozyme (equivalent to $1.8 \mathrm{mg} / \mathrm{kg}$ sunitinib) was safe but showed no antifibrotic effects.

Conclusion: Multikinase inhibitors like sunitinib can be of benefit in the treatment of fibrotic diseases, provided that their safety can be improved by strategies as presented in this paper, and sustained renal levels can be achieved.

Keywords: drug delivery, sunitinib, fibrosis, platinum linker

\section{Introduction}

Progression of untreated kidney diseases results in tubulointerstitial fibrosis, eventually leading to end-stage renal disease. ${ }^{1,2}$ Activation of proximal tubular cells is an important step in the pathogenesis of tubulointerstitial fibrosis. ${ }^{3}$ Activated proximal tubular cells secrete chemotactic proteins that attract macrophages and other immune cells. ${ }^{4}$ Tubular cell activation also leads to epithelial-to-mesenchymal transition (EMT) of proximal tubular epithelial cells and excessive production of extracellular matrix (ECM) components. As a result, normal tissue is replaced by scar tissue and the kidney function is decreased. ${ }^{1,5,6}$ Since currently used drugs such as angiotensinconverting enzyme inhibitors and angiotensin II receptor type 1 antagonists are only partially effective, ${ }^{7,8}$ there is an urgent need for drugs that halt or even reverse the profibrotic processes.

Multiple signaling pathways are involved in the activation of tubular cells in tubulointerstitial fibrosis. ${ }^{1,2}$ Simultaneous inhibition of these cascades by a multitargeted 
kinase inhibitor therefore seems an attractive strategy. Sunitinib is a multitargeted tyrosine kinase inhibitor approved for the treatment of metastatic renal-cell carcinoma and gastrointestinal stromal tumors and currently also under investigation for the treatment of other types of cancer.9-11 Compared with other kinase inhibitors, sunitinib interacts with high affinity (ie, $\mathrm{K}_{\mathrm{d}}<100 \mathrm{nM}$ ) with a broad range of kinases, ${ }^{12}$ including the platelet-derived growth factor receptors (PDGFR) PDGFR- $\alpha$ and $-\beta$ and the vascular endothelial growth factor receptors (VEGFR) VEGFR-1 and $-2 .^{9,10}$ Overactivation of the PDGFR kinase pathway has been associated with the development of renal fibrosis by stimulating the proliferation, migration, and survival of myofibroblasts. ${ }^{13,14}$ The VEGFR kinase pathway has also been linked to renal fibrosis, although less clearly than the PDGFR kinase pathway. ${ }^{15,16}$ Sunitinib has not yet been investigated for the treatment of renal fibrosis, but has successfully been used to treat experimental liver fibrosis. ${ }^{17} \mathrm{We}$ now propose to use a renally targeted sunitinib analog as an antifibrotic treatment in kidney fibrosis.

One main concern when using a multitargeted kinase inhibitor for the treatment of renal fibrosis is the possible increased risk of side effects compared with more selective kinase inhibitors. ${ }^{18}$ Sunitinib has been associated with many side effects, including severe cutaneous toxicities and cardiotoxicity. ${ }^{11,19-22}$ To avoid these side effects, targeted delivery of sunitinib to the target cells, ie, the proximal tubular cells of the kidneys, is a comprehensive approach. We have shown that small-molecule inhibitors can be delivered to the kidney by conjugation to lysozyme, ${ }^{23-25}$ a low molecular weight protein that is rapidly filtered through the glomeruli of the kidneys and subsequently taken up at the apical membrane of proximal tubular cells via megalin receptor-mediated internalization. ${ }^{26}$

Since sunitinib does not contain functional groups such as hydroxyl or primary amino groups that can be used for the coupling to lysozyme, we designed a sunitinib derivative that can be linked to lysozyme via the platinum (II)-based Universal Linkage System ${ }^{\mathrm{TM}}$ (ULS) (Kreatech Diagnostics, Amsterdam, The Netherlands). This platinum linker forms stable coordinative bonds with pyridyl groups or other types of aromatic nitrogens, and can be conjugated to thiol groups in proteinaceous carriers. ${ }^{27}$ One of the important properties of conjugates prepared with this type of linker is the prolonged retention of the delivered drug inside the target cells (ie, several days), as was demonstrated in pharmacokinetic studies in rats. Upon intravenous administration, the majority of the targeted drug persisted in the designated cells in the ULS-bound form..$^{25,28}$ In the current study, we therefore designed a sunitinib analog which retained its activity in the ULS-bound form, and thus could display its activity as a platinum conjugate upon delivery in the proximal tubular cells of the kidneys.

Sunitinib is a type I adenosine triphosphate (ATP)competitive kinase inhibitor that exerts its effects on target kinases by binding in and around the adenine region of the ATP-binding pocket. ${ }^{29}$ Structural binding studies of sunitinib have revealed that the oxindole moiety of sunitinib is localized deep in the ATP-binding pocket of target kinases, where it is bound to the adenine region via hydrophobic interactions, while the $\mathrm{N}$-2-(diethylamino)ethylene side chain is exposed outwards. ${ }^{30,31}$ We recently demonstrated that this group can be replaced by a pyridyl side chain and that platinum conjugates of such a sunitinib analog retain activity. ${ }^{32}$ Figure 1 shows the chemical structure of this newly developed sunitinib analog called 17864 . In the current study we investigated the coupling of 17864-ULS to the renal carrier lysozyme, as well as the in vitro capability of platinum-bound 17864 to inhibit kinase activity. The in vivo accumulation of 17864ULS-lysozyme in the kidneys was studied after intravenous administration to mice. We also investigated the antifibrotic effects of sunitinib and 17864-ULS-lysozyme in mice with unilateral ureteral obstruction (UUO)-induced tubulointerstitial fibrosis.

\section{Materials and methods Materials and chemicals}

The sunitinib analog 17864 was synthesized according to Sun et al by Vichem Chemie (Budapest, Hungary). ${ }^{33}$ Sunitinib malate was purchased from Sequoi Research Products (Pangbourne, UK). The ULS cis-
A

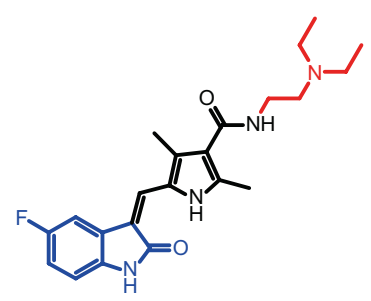

Sunitinib
B

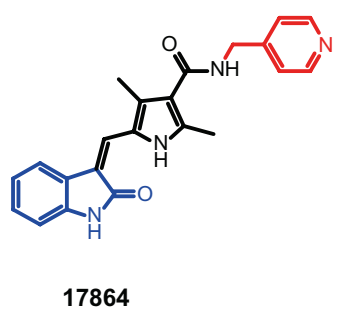

Figure I Structures of the multitargeted tyrosine kinase inhibitor sunitinib $(\mathbf{A})$ and the ULS-linkable sunitinib derivative 17864 (B). The aliphatic $N$-2-(diethylamino) ethylene sidechain of sunitinib has been replaced by a N-4-methylpyridine side chain (red). When binding to target kinases, the oxindole moiety (blue) of the drug is located in the adenine region of the ATP-binding pocket, while the $\mathrm{N}$-2-(diethylamino) ethylene moiety or N-4-methylpyridine are protruding outwards.

Abbreviation: ATP, adenosine triphosphate. 
[Pt(ethylenediamine)nitrate-chloride] was synthesized from cis-[Pt(ethylenediamine)dichloride] as described elsewhere. ${ }^{34}$ Lysozyme from hen egg white was purchased from Fluka (Zwijndrecht, The Netherlands). The TaqMan ${ }^{\circledR}$ Universal PCR Master Mix, No AmpErase ${ }^{\circledR}$ UNG, and The TagMan ${ }^{\circledR}$ Gene Expression Assays Mm00446973_m1, Mm00435860_m1, Mm00483888_m1, Mm01256734_m1, and Mm00441242_ $\mathrm{m} 1$ for the detection of, respectively, TATA-binding protein (TBP), plasminogen activator inhibitor-1 (PAI-1), Collagen 1A2, fibronectin, and monocyte chemotactic protein-1 (MCP1) were purchased from Applied Biosystems (Nieuwerkerk aan den IJssel, The Netherlands). Goat anti-mouse megalin (P-20), rabbit anti-mouse p-PDGFR- $\beta$, and rabbit anti-mouse vimentin polyclonal antibodies were purchased from Santa Cruz (Heidelberg, Germany). Rabbit anti-hen egg white lysozyme polyclonal antibody was purchased from Millipore (Amsterdam, The Netherlands). Alexa fluor 488 donkey anti-goat and Alexa fluor 647 donkey anti-rabbit secondary antibodies were purchased from Invitrogen (Breda, The Netherlands). Rabbit anti-mouse $\beta$-actin polyclonal antibody and horseradish peroxidase (HRP)-conjugated goat anti-rabbit secondary antibody were purchased from Cell Signaling Technology (Leiden, The Netherlands). Mouse anti-human phosphotyrosine (PY20) (HRP) monoclonal antibody, rabbit anti-mouse $\alpha$-smooth muscle actin (SMA) antibody, and rabbit anti-mouse collagen type IV antibody were purchased from Abcam (Cambridge, UK). BrightVision HRP-conjugated goat anti-rabbit secondary antibody was purchased from Immunologic (Duiven, The Netherlands).

\section{Synthesis of I 7864-ULS-lysozyme}

Sunitinib analog 17864 was coupled to the platinum (II)based linker ULS by incubating equimolar amounts (ie, $107 \mu \mathrm{mol}$ ) of 17864 and ULS in $9 \mathrm{~mL}$ dimethylformamide for 4 hours at $37^{\circ} \mathrm{C}$. To confirm the formation of the 17864 ULS 1:1 adduct, the final product was analyzed with mass spectrometry and ${ }^{195} \mathrm{Pt}$-nuclear magnetic resonance (NMR). To introduce thiol groups onto the protein's surface that could react with the platinum linker, lysozyme $(10 \mathrm{mg} / \mathrm{mL}$ in phosphate-buffered saline $[\mathrm{PBS}]$ ) was reacted with a $3 \times$ molar excess of BOC- $L$-methionine $N$-hydroxysuccinimide ester $(50 \mathrm{mg} / \mathrm{mL}$ in dimethyl sulfoxide [DMSO]) for 1 hour at ambient temperature. Purification of the product was performed by dialysis against water. Methionine-lysozyme was lyophilized and characterized by matrix-assisted laser desorption-ionization time-of-flight (MALDI-TOF) mass spectrometry. Lastly, methionine-lysozyme was incubated with a $3 \times$ molar excess of $17864-\mathrm{ULS}$ in $0.02 \mathrm{M}$ tricine/sodium nitrate buffer $\mathrm{pH} 8.5$ overnight at $37^{\circ} \mathrm{C}$. The 17864-ULS-lysozyme conjugate obtained was purified by dialysis at $4^{\circ} \mathrm{C}$ against $10 \%$ dimethyl sulfoxide in demineralized water, followed by extensive dialysis against demineralized water. The purified conjugate was lyophilized and stored at $-20^{\circ} \mathrm{C}$ until further use.

\section{Characterization of I 7864-ULS-lysozyme}

For the characterization of 17864-ULS-lysozyme an $8 \mathrm{mg} / \mathrm{mL}$ stock solution in water was prepared and subsequently filtered through a $0.2 \mu \mathrm{m}$ filter. The concentrations of 17864-ULS and lysozyme in this solution were measured to establish the drug/carrier ratio in the final product. Lysozyme was measured using the Micro BCA ${ }^{\mathrm{TM}}$ Protein Assay Kit (Thermo Scientific, Etten-Leur, The Netherlands). For the analysis of the amount of 17864-ULS conjugated to lysozyme, the drug was displaced from the linker with an excess of potassium thiocyanate $(\mathrm{KSCN})$ and the concentrations of liberated 17864 were determined with high-performance liquid chromatography. Briefly, the stock solution was diluted six times in a mixture of $50 \% \mathrm{PBS}, 50 \%$ acetonitrile (ACN), and $0.05 \%$ trifluoroacetic acid (TFA) containing a final concentration of $0.5 \mathrm{M} \mathrm{KSCN}$ and incubated for 24 hours at $80^{\circ} \mathrm{C}$. After reaching ambient temperature, $200 \mu \mathrm{L} \mathrm{ACN}$ with $0.1 \%$ TFA was added to the samples. The samples were mixed by vortexing and centrifuged for 4 minutes at 19,500 $\mathrm{g}$. Fifty microliters of the supernatants were injected in a reversed phase high-performance liquid chromatography system consisting of a Waters 2695 separations module, a Waters 2487 dual $\lambda$ absorbance detector and a Waters SunFire ${ }^{\mathrm{TM}}$ C18 column $(4.6 \times 150 \mathrm{~mm}, 5 \mu \mathrm{m}$ particle size) (Waters, Milford, MA). Empower 2 software (Waters) was used for data recording. The column and sample temperature were maintained at $30^{\circ} \mathrm{C}$ and $20^{\circ} \mathrm{C}$, respectively. A gradient was used with eluent $\mathrm{A}$ consisting of $5 \% \mathrm{ACN} / 95 \%$ water $/ 0.1 \%$ TFA (w/w/w) and eluent B consisting of ACN/0.1\% TFA $(\mathrm{w} / \mathrm{w})$. The composition of the mobile phase was linearly changed from $100 \%$ to $20 \%$ eluent A in 25 minutes using a flow rate of $1 \mathrm{~mL} / \mathrm{minute}$. Sunitinib analog 17864 was detected at $431 \mathrm{~nm}$.

\section{Cell culture}

The immortalized human renal proximal tubule epithelial cell line (HK-2) (American Type Culture Collection, LGC Standards, Teddington, UK) was cultured in Dulbecco's Modified Eagle's Medium containing $3.7 \mathrm{~g} / \mathrm{L}$ sodium bicarbonate, $1.0 \mathrm{~g} / \mathrm{L}$ glucose, supplemented with $10 \%$ (v/v) fetal bovine serum, penicillin (100 U/L), streptomycin $(100 \mu \mathrm{g} / \mathrm{mL})$, 
and amphotericin $\mathrm{B}(0.25 \mu \mathrm{g} / \mathrm{mL})$ at $37^{\circ} \mathrm{C}$ with $5 \% \mathrm{CO}_{2}$ in humidified air. All cell culture-related media were obtained from PAA Laboratories GmbH (Pasching, Austria).

\section{In vitro inhibition of tyrosine kinase activity}

The inhibitory effects of 17864-ULS-lysozyme on the phosphorylation of tyrosine kinases were studied after internalization in HK-2 cells seeded onto 96-well plates $\left(1.5 \times 10^{4}\right.$ cells/well). Cells were serum-starved overnight and subsequently incubated with $10 \mu \mathrm{M} 17864,17864-U L S$, methionine-modified lysozyme, 17864-ULS-lysozyme, or sunitinib malate. After 24 hours, cells were washed thrice with PBS and lysed with mammalian protein extraction reagent containing protease- and phosphatase-inhibitors. Protein concentrations of the lysates were determined using the micro bicinchoninic acid (BCA) ${ }^{\mathrm{TM}}$ assay (Pierce Biotechnology, Thermo Scientific, Rockford, IL).

The phosphorylation activity of kinases present in the lysates and inhibition by the intracellular accumulated inhibitors was investigated by addition of an equal volume of $10 \mu \mathrm{M}$ ATP in Abl kinase assay buffer (consisting of $50 \mathrm{mM}$ 2-amino-2-(hydroxymethyl)-1,3-propanediol (Tris)- $\mathrm{HCl}[\mathrm{pH}$ 7.5], $10 \mathrm{mM} \mathrm{MgCl}_{2}, 1 \mathrm{mM}$ ethyleneglycoltetraacetic acid, $2 \mathrm{mM}$ dithiothreitol (DTT), and 0.01\% Brij-35). After incubation at $37^{\circ} \mathrm{C}$ for 60 minutes, the reaction was terminated by adding reducing sample buffer (Invitrogen) containing a final concentration of $40 \mathrm{mM}$ DTT and $0.1 \%(\mathrm{w} / \mathrm{v})$ sodium dodecyl sulfate (SDS). Total protein $(10 \mu \mathrm{g})$ was separated by SDS-PAGE using a NuPAGE ${ }^{\circledR} 4 \%-12 \%$ Bis-Tris precast gel and NuPAGE ${ }^{\circledR} 3$-( $N$-morpholino)propanesulfonic acid (MOPS)-SDS running buffer (Invitrogen). Proteins were transferred onto a $0.45 \mu \mathrm{m}$ Immobilon ${ }^{\mathrm{TM}}$-P polyvinylidene fluoride membrane (Millipore) by wet blotting. The transfer buffer consisted of $25 \mathrm{mM}$ Tris, $192 \mathrm{mM}$ glycine, and 10\% methanol (v/v) and a transfer voltage was used of $100 \mathrm{~V}$ for 1 hour. After 1 hour blocking at room temperature with 3\% $(\mathrm{w} / \mathrm{v})$ bovine serum albumin (BSA) in Tris-buffered saline (TBS) with $0.1 \%(\mathrm{v} / \mathrm{v})$ Tween-20 (TBS with $0.1 \%$ [v/v]; Tween-20 will be further referred to as TBS/T), the membrane was incubated for 1 hour at room temperature with mouse anti-human phosphotyrosine (PY20) (HRP) monoclonal antibody (1:500) in 3\% BSA in TBS/T. The membrane was washed with TBS/T and proteins were visualized using the SuperSignal $^{\circledR}$ West Femto Maximum Sensitivity Substrate Kit (Thermo Scientific). Band densities were determined on a Gel Doc XRS Imaging system with Quantity One analysis software (Bio-Rad, Hercules, CA).
The inhibitory effects of 17864, 17864-ULS, and 17864ULS-lysozyme were also studied by spiking the inhibitors to lysates of serum-starved control HK-2 cells. $0.1 \mathrm{mg} / \mathrm{mL}$ HK-2 cell lysates were preincubated with $2 \mu \mathrm{M}$ of the compounds for 30 minutes at room temperature after which the cell lysates were stimulated with $1 \mu \mathrm{M}$ ATP and processed as described above.

\section{In vitro cytotoxicity}

HK-2 cells were seeded $\left(4 \times 10^{3}\right.$ cells/well in a total volume of $100 \mu \mathrm{L}$ complete medium) in 96 -well plates 24 hours prior to addition of the samples. Cell were then incubated for 24 hours with methionine-lysozyme, sunitinib malate, and 17864-ULSlysozyme ( $n=6$ for all samples) up to a concentration of $50 \mu \mathrm{M}$ and under normal culture conditions. Untreated HK-2 cells were used as a control. The cytotoxicity of the samples was established using the sulforhodamine B (SRB) colorimetric assay. ${ }^{35}$ After incubation, HK-2 cells were fixed in situ by incubation with $50 \mu \mathrm{L} /$ well $12.5 \%$ (w/v) trichloroacetic acid in demineralized water for 1.5 hours at $4^{\circ} \mathrm{C}$. Supernatants were removed from the wells and the cells were washed four times with normal water and subsequently air-dried. Staining was performed by incubation of the cells with $100 \mu \mathrm{L} /$ well $0.4 \%(\mathrm{w} / \mathrm{v}) \mathrm{SRB}$ in $1 \%$ acetic acid in demineralized water for 15 minutes at room temperature, under shaking. The SRB solution was removed from the wells and the cells were washed four times with $1 \%(\mathrm{v} / \mathrm{v})$ acetic acid in demineralized water. After air-drying, cells were incubated with $200 \mu \mathrm{L} /$ well $10 \mathrm{mM}$ Trizma ${ }^{\circledR}$ base (Sigma-Aldrich, St Louis, MO) in demineralized water for 15 minutes at room temperature, under shaking. The optical density was measured at $550 \mathrm{~nm}$. Nonlinear regression curve-fitting with GraphPad Prism software (v 5; GraphPad Software Inc, San Diego, CA) was used to calculate the half maximal inhibitory concentration of sunitinib malate.

\section{Animal experiments}

All in vivo experiments were performed in normal male C57BI/6 J mice obtained from Harlan (Zeist, The Netherlands). Mice were ordered with a body weight of 13-25 g and were used within 4 weeks after arrival. The mice were housed in cages in a 12-hour light and 12-hour dark cycle and given food and water ad libitum. Experimental protocols for pharmacokinetic and efficacy studies were approved by the animal ethics committee of the Utrecht University, The Netherlands.

\section{Pharmacokinetic studies}

The pharmacokinetics of 17864-ULS-lysozyme was studied in mice and compared with the pharmacokinetics of 
sunitinib malate. Mice received a single intravenous injection of either 17864-ULS-lysozyme ( $\mathrm{n}=17 ; 20 \mathrm{mg} / \mathrm{kg})$ or an equimolar dose of sunitinib malate $(\mathrm{n}=15 ; 1.7 \mu \mathrm{mol} / \mathrm{kg}$, $0.9 \mathrm{mg} / \mathrm{kg}$ ). At 1 minute after administration of the compounds, a blood sample was taken via a cheek puncture. Animals were sacrificed at the indicated time points. Blood samples were collected, centrifuged twice at $5500 \mathrm{~g}$ for 15 minutes at $4^{\circ} \mathrm{C}$ and stored at $-80^{\circ} \mathrm{C}$ until further analysis as described below. Kidneys were removed and stored at $-80^{\circ} \mathrm{C}$ until further processing as described below. Plasma and renal drug levels were expressed as a percentage of the injected dose. The calculation of the percentage of the dose in the total plasma volume was based on an average plasma volume of $0.05 \mathrm{~mL} / \mathrm{g}$ of mouse body weight. ${ }^{36}$ Absorption and elimination half-lives, distribution volumes, and areas under the curves were calculated by curve-fitting with a twocompartment model with Multifit pharmacokinetic software (University of Groningen, Groningen, The Netherlands).

\section{Immunostaining of kidney sections}

Uptake of 17864-ULS-lysozyme in proximal tubular cells was investigated by immunostaining of the carrier part, ie, chicken egg-white lysozyme, and the megalin receptor which is expressed on proximal tubular cells. Paraffin-embedded kidney sections of $4 \mu \mathrm{m}$ were deparaffinized in xylene and hydrated in a graded series of alcohol baths. Enzyme pretreatment was performed in Tris (4.84 g/L)/EDTA (372 mg/L) buffer with $\mathrm{pH} 9$. Sections were subsequently incubated with goat anti-mouse megalin primary antibody (1 hour), Alexa fluor 488 donkey anti-goat secondary antibody (30 minutes), rabbit anti-hen egg white lysozyme primary antibody (1 hour), and Alexa fluor 647 donkey anti-rabbit secondary antibody (30 minutes). Antibodies were diluted in PBS with $1 \%$ BSA and $1 \%$ azide. Sections were washed with PBS containing $0.05 \%$ tween-20 (PBS/0.05T). Stained sections were analyzed using confocal laser scanning microscopy.

\section{Liquid chromatography-tandem mass spectrometry (LC-MS/MS) analysis of sunitinib}

Plasma and renal sunitinib concentrations were measured according to the following protocol. Calibration standards were prepared in a concentration range of $10 \mathrm{ng} / \mathrm{mL}-1 \mu \mathrm{g} / \mathrm{mL}$ sunitinib malate in blank human plasma and $10-500 \mathrm{ng} / \mathrm{mL}$ in blank kidney homogenate. Plasma samples collected at 1 minute after administration of sunitinib malate were diluted two times with blank human plasma; other samples were processed undiluted. Blank kidney homogenate was prepared by homogenizing kidneys of non-treated C57BI/6 J mice in $4 \%(\mathrm{w} / \mathrm{v}) \mathrm{BSA}$ in demineralized water in a final concentration of $0.1 \mathrm{~g}$ tissue $/ \mathrm{mL}$. The kidney homogenates of the mice injected with sunitinib malate were prepared in the same manner. Blank human plasma and kidney homogenate were used as negative control.

A $100 \mu \mathrm{L}$ sample was spiked with $50 \mu \mathrm{L}$ of a 4-hydroxybenzophenone internal standard solution (50 $\mu \mathrm{g} / \mathrm{mL}$ in methanol). Sunitinib was extracted from the biological matrices (ie, plasma and kidney tissue) using $2 \times 1 \mathrm{~mL}$ tert-butyl methyl ether (TBME). After addition of TBME, samples were mixed vigorously and centrifuged for 5 minutes at $7500 \mathrm{~g}$. The aqueous layers were frozen in a bath of ethanol with dry ice and the TBME layers were collected. Evaporation of the TBME (in a rotational vacuum concentrator [RVC 2-25; Martin Christ GMBH, Osterode am Harz, Germany] for 45 minutes at $45^{\circ} \mathrm{C}$ ) was followed by reconstitution of the samples in $100 \mu \mathrm{L}$ ACN containing $0.1 \%$ TFA. After 3 minutes centrifugation at 21,000 $\mathrm{g}$, supernatants were diluted three times with demineralized water before analysis with LC-MS/MS. The LC-MS/MS equipment and general MS/MS setting were reported previously by Sparidans et al. ${ }^{37}$ Partial-loop injections $(2 \mu \mathrm{L})$ were made on an Aquity UPLC ${ }^{\circledR}$ BEH C18 column $(30 \times 2.1 \mathrm{~mm}$, $\mathrm{d}_{\mathrm{p}}=1.7 \mu \mathrm{m}$, Waters, Milford, MA) with the corresponding VanGuard pre-column (Waters, $5 \times 2.1 \mathrm{~mm}, \mathrm{~d}_{\mathrm{p}}=1.7 \mu \mathrm{m}$ ). The column temperature was maintained at $40^{\circ} \mathrm{C}$ and the autosampler sample rack compartment was maintained at $4^{\circ} \mathrm{C}$. The eluent comprised a mixture of two solvents: $0.1 \%$ $(\mathrm{v} / \mathrm{v})$ formic acid in water (A) and methanol (B), pumped at $0.5 \mathrm{~mL} /$ minute. The amount of solvent $\mathrm{B}$ was increased from 20 to $60 \%$ during 2 minutes after injection, followed by flushing the column for 0.5 minutes with $90 \%$ methanol, and reconditioning the column at $20 \%$ methanol for 1.5 minutes. The whole eluate was transferred into the electrospray ionization source, starting at 0.7 minutes after injection by switching the MS inlet valve. The selected reaction monitoring mode was used with argon as the collision gas at 1.5 mTorr. Dwell times were 0.2 seconds for sunitinib and 0.1 second for the internal standard. The tube lens offset was $92 \mathrm{~V}$ for sunitinib and $100 \mathrm{~V}$ for the internal standard. Sunitinib was monitored at $m / z 399.24 \rightarrow 283.15$ at $-24 \mathrm{~V}$ collision energy; the internal standard at $\mathrm{m} / \mathrm{z} 199.00 \rightarrow 121.00$ at $-15 \mathrm{~V}$.

\section{LC-MS/MS analysis of I7864-ULS- lysozyme}

Total 17864 (ie, the combined level of 17864-ULSlysozyme + 17864-ULS + released 17864) and free 17864 (ie, 
released 17864 levels) were measured in plasma and kidney homogenate. Analyses were performed using the sunitinib malate protocol with minor modifications.

For the measurement of the total 17864 concentrations in plasma and kidneys, samples spiked with the internal standard were incubated at $80^{\circ} \mathrm{C}$ for 24 hours with an equivolume of $1 \mathrm{M} \mathrm{KSCN}$ in PBS to displace platinum-bound 17864 from the ULS linker. Next, 17864 was extracted with TBME. Plasma samples collected at 1 minute after administration of 17864-ULS-lysozyme were diluted three times with blank human plasma, all other samples were processed undiluted.

For the 17864 LC-MS/MS analysis, the same equipment and column were used as for sunitinib, with some modifications in the conditions. The amount of solvent $\mathrm{B}$ was increased from $10 \%$ to $70 \%$ during the 3 minutes after injection, followed by flushing the column for 0.5 minutes with $70 \%$ methanol, and reconditioning the column with $10 \%$ methanol for 1.5 minutes. The whole eluate was transferred into the electrospray ionization source, starting at $0.8 \mathrm{~min}-$ utes after injection by switching the MS inlet valve, until 4 minutes after injection. The selected reaction monitoring mode was used with argon as the collision gas at 2.0 mTorr and 40 millisecond dwell times. Sunitinib analog 17864 was monitored at $\mathrm{m} / \mathrm{z} 373.14 \rightarrow 239.17$ at $-18 \mathrm{~V}$ collision energy and the tube lens offset was $108 \mathrm{~V}$.

\section{Antifibrotic effects of sunitinib and I7864-ULS-lysozyme in UUO-induced fibrosis}

Antifibrotic effects of sunitinib malate and 17864-ULSlysozyme have been studied in mice with UUO-induced tubulointerstitial fibrosis. Surgically induced ureteral obstruction was performed according to the following protocol. Under isoflurane anesthesia ( $3 \%$ in $100 \% \mathrm{O}_{2} ; 1 \mathrm{~L} /$ minute $)$ the ureter of the left kidney was ligated at two places with silk (5-0). Mice were sacrificed after 3 days' ureteral obstruction.

Mice were randomly divided into two control groups ( $n=6$ per group) and three treatment groups $(n=7$ per group). The first control group consisted of normal mice without UUO-induced tubulointerstitial fibrosis and the second control group of mice with UUO-induced tubulointerstitial fibrosis without treatment. In the treatment groups, mice with UUO-induced renal fibrosis were treated with a single intravenous injection of $40 \mathrm{mg} / \mathrm{kg} 17864-$ ULS-lysozyme (corresponding to $3.4 \mu \mathrm{mol} / \mathrm{kg} 17864$ ), an equimolar single intravenous injection of sunitinib malate (3.4 $\mu \mathrm{mol} / \mathrm{kg} ; 1.8 \mathrm{mg} / \mathrm{kg}$ ) or three daily intraperitoneal injections of $50 \mathrm{mg} / \mathrm{kg}$ sunitinib malate $(94 \mu \mathrm{mol} / \mathrm{kg})$.

\section{Western blot analysis}

The activation of PDGFR- $\beta$ after 3 days ureteral obstruction and the inhibitory effects of the intrinsically active 17864ULS-lysozyme conjugate on the activated PDGFR- $\beta$ levels were detected in the renal cortex by Western blot analysis of phosphorylated PDGFR- $\beta$ (p-PDGFR- $\beta$ ). Cortex homogenates were prepared by homogenizing a small part of the cortex in $400 \mu \mathrm{L}$ RIPA buffer supplemented with proteaseand phosphatase inhibitors and EDTA. After measuring the protein content of the samples with the Micro BCA ${ }^{\mathrm{TM}}$ Protein Assay Kit (Thermo Scientific), $7 \mu \mathrm{L} 4 \times$ SDS-containing loading buffer was added to an aliquot of the samples corresponding with $50 \mu \mathrm{g}$ protein. Demineralized water was added to adjust the total volume of the samples to $30 \mu \mathrm{L}$ and the samples were heated for 7 minutes at $95^{\circ} \mathrm{C}$. Proteins were separated by SDS-PAGE in a similar manner as described above for the investigation of the in vitro activity of the conjugate. After transferring the proteins onto a polyvinylidene fluoride membrane, the part containing the proteins with a molecular size $>100 \mathrm{kDa}$ was used for the detection of $\mathrm{p}$-PDGFR- $\beta$ and the part of the membrane containing the proteins with a molecular size $<100 \mathrm{kDa}$ for the detection of $\beta$-actin. Membranes were blocked for 1 hour at room temperature in blocking buffer (ie, 5\% nonfat dry milk in TBS/T) before overnight incubation at $4^{\circ} \mathrm{C}$ with the primary antibodies (ie, rabbit anti-mouse p-PDGFR- $\beta$ (Tyr 740) (1:200) or rabbit anti-mouse $\beta$-actin (1:1000) polyclonal antibody) in TBS/T with $5 \%(\mathrm{w} / \mathrm{v})$ BSA. Next, membranes were incubated for 1 hour at room temperature with HRP-conjugated goat antirabbit secondary antibody (1:1000 in TBS/T with 5\% (w/v) nonfat dry milk), followed by the detection of p-PDGFR- $\beta$ and $\beta$-actin using the SuperSignal ${ }^{\circledR}$ West Femto Maximum Sensitivity Substrate Kit (Thermo Scientific). Wash steps were performed with TBS/T.

\section{Gene expression analysis}

The inhibitory effects of 17864-ULS-lysozyme on the mRNA expression of collagen 1A2, PAI-1, fibronectin, and MCP-1 in the whole kidneys and the cortex have been analyzed by quantitative reverse transcription polymerase chain reaction (qRTPCR). Total RNA was isolated from $>1.8 \mathrm{mg}$ tissue using the RNeasy KIT from QIAGEN (Venlo, The Netherlands). The RNA content in the samples was measured by UV-detection with the NanoDrop 1000 (NanoDrop, Wilmington, DE). For all samples, the ratio between the absorbance at $260 \mathrm{~nm}$ and $280 \mathrm{~nm}$ was higher than 1.8, indicating that the RNA samples were not contaminated with DNA. After RNA extraction, $300 \mathrm{ng}$ of RNA was used for the synthesis of complementary 
DNA (cDNA). For the synthesis of cDNA the RevertAid ${ }^{\mathrm{TM}}$ Premium First Strand cDNA Synthesis Kit from Fermentas (Sankt Leon-Rot, Germany) was used. The obtained cDNA samples were diluted ten times with Milli-Q water (Millipore) before use. For the qRT-PCR analyses, each sample consisted of $2.5 \mu \mathrm{L} 10$ times diluted cDNA, $0.625 \mu \mathrm{L}$ TagMan ${ }^{\circledR}$ Gene Expression Assay, 6.25 $\mu \mathrm{L}$ TaqMan ${ }^{\circledR}$ Universal PCR Master Mix (both from Applied Biosystems), and 3.125 $\mu \mathrm{L}$ Milli-Q water. The analyses were performed using the Applied Biosystems ABI PRISM ${ }^{\circledR} 7900 H T$ Sequence Detection System (Nieuwerkerk aan den IJssel, The Netherlands). Sequence Detection System Software (v 2.2) was used for data analysis. Statistical analysis of the results was performed using one-way analysis of variance (ANOVA), with $P<0.05$ as the minimal level of significance.

\section{Immunostaining of fibrotic markers in kidney sections}

Paraffin-embedded kidney sections of $3 \mu$ m were deparaffinized in xylene and hydrated in a graded series of alcohol baths. After 15 minutes incubation in blocking buffer (consisting of 1 part hydrogen peroxide $30 \%$ and 19 parts of a solution containing $8.32 \mathrm{~g} / \mathrm{L}$ citric acid, $21.52 \mathrm{~g} / \mathrm{L}$ disodium hydrogen phosphate dehydrate, and $2 \mathrm{~g} / \mathrm{L}$ sodium azide, $\mathrm{pH}$ 5.8), kidney sections were boiled for 15 minutes in $10 \mathrm{mM}$ citrate buffer pH 6.0 (for collagen IV and vimentin) or Tris/EDTA buffer (containing $4.84 \mathrm{~g} / \mathrm{L}$ Tris and $372 \mathrm{mg} / \mathrm{L}$ EDTA) pH 9.0 (for $\alpha$-SMA). Back at room temperature, kidney sections were washed with PBS containing $0.05 \%(\mathrm{v} / \mathrm{v})$ Tween $-20^{\circledR}$ (Sigma-Aldrich) (PBS/0.05T) and incubated for 1 hour with the primary antibodies at room temperature. All primary antibodies were diluted in PBS with 1\% (w/v) BSA; rabbit antimouse $\alpha$-SMA 1:400, rabbit anti-mouse collagen IV 1:400, and rabbit anti-mouse vimentin 1:200. Kidney sections were subsequently washed with PBS/0.05T, incubated for $30 \mathrm{~min}-$ utes at room temperature with undiluted HRP-conjugated BrightVision goat anti-rabbit secondary antibody, washed with PBS, and incubated for 10 minutes with 3,3-diaminobenzidine $(\mathrm{DAB})$ in the presence of hydrogen peroxide (to $1 \mathrm{~mL}, 6 \mathrm{~g} / \mathrm{L}$ DAB in demineralized water, $9 \mathrm{~mL}$ phosphate/ citrate buffer, $\mathrm{pH} 9.0$, and $10 \mu \mathrm{L}$ hydrogen peroxide $30 \%$ were added). Nuclei were stained by washing the kidney sections three times with demineralized water, placing the sections for 10-15 seconds in undiluted hematoxylin solution (Gill's No 2), and rinsing them with normal tap water for at least 10 minutes. Kidney sections were dehydrated in a graded series of alcohol baths and xylene, mounted, and analyzed using light microscopy.

\section{Results and discussion}

\section{Synthesis and characterization of I7864-ULS-lysozyme}

Figure 2 shows the reaction scheme followed for the preparation of 17864-ULS-lysozyme. The successful formation of a coordinative bond between the platinum (II) linker and the aromatic nitrogen of the pyridine ring in 17864 was proven by mass spectrometry and ${ }^{195} \mathrm{Pt}-\mathrm{NMR}$ analysis. ${ }^{195} \mathrm{Pt}-\mathrm{NMR}$ analysis showed a peak at -2493 ppm which, as has been demonstrated for different drug-ULS-carrier conjugates, ${ }^{38,39}$ is characteristic for a $\mathrm{Pt}-\mathrm{N}_{3}$ coordination. The fact that the sunitinib analog SU6668 (ie, [Z]-3-[2,4-dimethyl-5-([2oxoindolin-3-ylidene]methyl)-1 $H$-pyrrol-3-yl]propanoic acid) cannot be coordinated to the ULS linker indirectly proves that the ULS linker in 17864-ULS is coordinated to the pyridine nitrogen in 17864. Mass spectrometry demonstrated that the reaction of 17864 to ULS yielded $80 \%$ of the desired 17864 ULS 1:1 adduct (detected $\mathrm{ESI}^{+} \mathrm{MS}$ peaks: $m / z 663$ of $[\mathrm{M}]^{+}$,

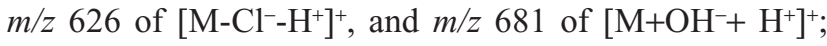
$\mathrm{M}=17864-\mathrm{ULS}$ with chloride ion as second ligand attached to the platinum atom (Figure 2)). Besides the 1:1 adduct,

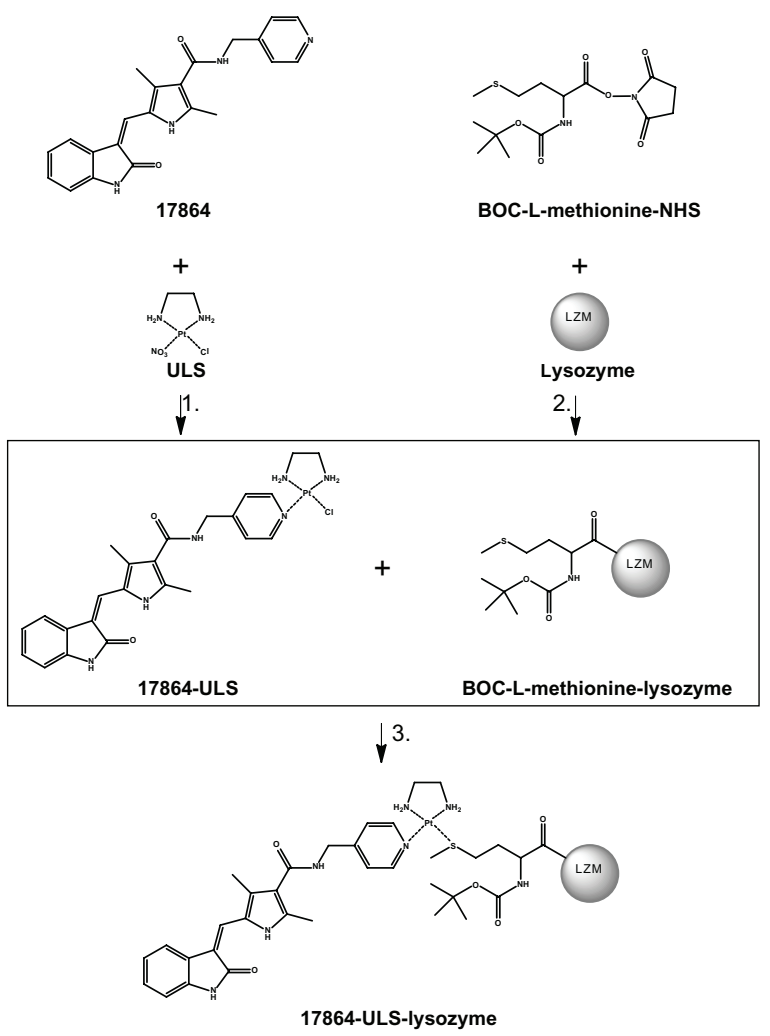

Figure 2 Synthesis scheme of 17864-ULS-lysozyme. The multitargeted kinase inhibitor 17864 was coupled to the ULS platinum linker (I). The carrier protein lysozyme was reacted with BOC-L-methionine $\mathrm{N}$-hydroxysuccinimide to introduce thiol groups (2). Conjugation of I7864-ULS to methionine-modified lysozyme yielded the final renal-specific I7864-ULS-lysozyme conjugate (3). 
the product also contained $14 \%$ of the dimeric adduct, ie, (17864) $)_{2}$-ULS. This disubstituted drug-ULS-drug adduct cannot react with the renal carrier protein and was removed from the product in the final dialysis step of 17864-ULS-lysozyme. Thiol groups were introduced on the surface of lysozyme by modification of the carrier protein with methionine residues. MALDI-TOF mass spectrometric analysis of the modified lysozyme yielded peaks at $m / z 14,539,14,772,15,006$, and 15,238 , corresponding to BOC-methionine-lysozyme with, respectively, one, two, three, and four methionine residues attached to the renal carrier protein (theoretical masses: $14,537,14,769,15,000$, and 15,231 Da, respectively). This allowed the conjugation of 17864-ULS at a 1.2:1 coupling ratio under the applied conditions with a $3: 1$ synthesis ratio of drug-ULS: lysozyme.

\section{In vitro activity of I 7864-ULS-lysozyme after uptake in HK-2 cells}

We investigated the multikinase inhibitory effects of 17864-ULS-lysozyme after internalization and intracellular processing by HK-2 cells by analyzing its potency to reduce the level of phosphorylation activity of tyrosine kinases.
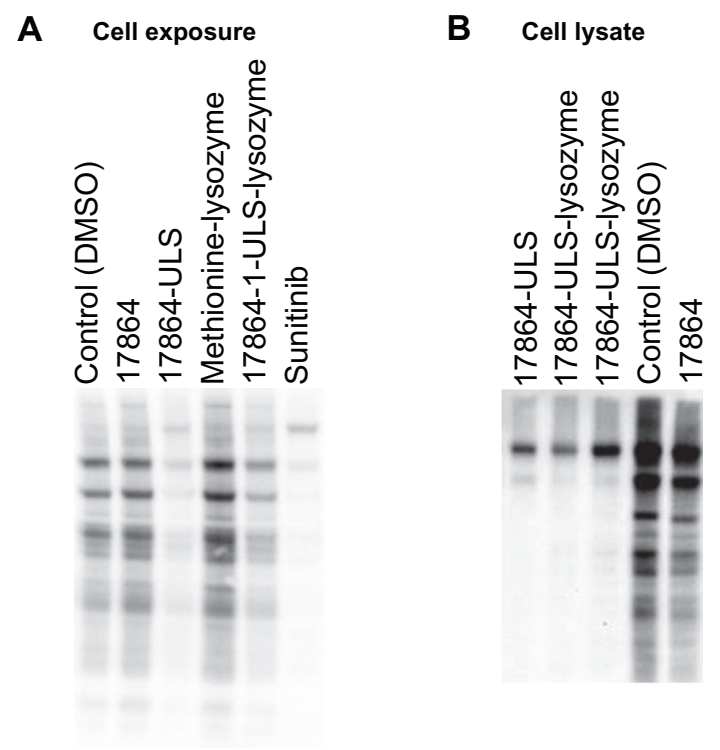

Figure 3 (A) HK-2 cells were incubated with $10 \mu \mathrm{M}$ 17864, 17864-ULS, methionine-modified lysozyme, I7864-ULS-lysozyme and sunitinib, and with $0.1 \%$ $(\mathrm{v} / \mathrm{v})$ DMSO (control). After 24 hours of incubation, the cells were lysed and ATP was added to stimulate the phosphorylation of tyrosine kinases. Western blot analysis was performed to investigate the inhibitory effects of the compounds on the phosphorylation of tyrosine kinases. (B) Freshly prepared HK-2 cell lysates were spiked with $2 \mu \mathrm{M}$ 17864, I7864-ULS, and I7864-ULS-lysozyme (two batches) and with $0.1 \%(\mathrm{v} / \mathrm{v})$ DMSO (control). After 30 minutes of incubation, ATP was added to stimulate the phosphorylation of tyrosine kinases. Western blot analysis was performed to investigate the inhibitory effects of the compounds on the phosphorylation of tyrosine kinases.

Abbreviations: ATP, adenosine triphosphate; DMSO, dimethyl sulfoxide.
Figure 3A shows the anti-phosphotyrosine Western blot of HK-2 cells exposed to $10 \mu \mathrm{M}$ of $17864,17864-U L S$, methionine-lysozyme, 17864-ULS-lysozyme, and sunitinib malate, respectively. Both sunitinib and 17864-ULS-lysozyme strongly inhibited multiple kinases, as can be deduced from the strong reduction in tyrosine-phosphorylated proteins. The inhibitory effects of 17864-ULS were almost as strong as the inhibitory effects observed with sunitinib. Unexpectedly, unmodified 17864 did not reduce the phosphorylation of tyrosine kinases in this experimental set-up. We conducted an additional experiment, in which the compounds were spiked directly into the cell lysate. Differences in uptake and cytosolic delivery of the compounds were thereby avoided. Again, unmodified 17864 showed only a minor reduction in tyrosine phosphorylation, while a strong inhibition was observed with $2 \mu \mathrm{M}$ of both 17864-ULS and 17864-ULS-lysozyme (Figure 3B). Of note, 17864 showed proper inhibitory activity against recombinant PDGFR- $\beta$, with a similar half maximal inhibitory concentration as sunitinib and 17864-ULS. ${ }^{32}$ We therefore believe that the lower activity in the present assays relates to differences in selectivity profiles between the compounds versus other kinases than the ones tested so far. Despite the relatively lower activity of 17864 itself, our results demonstrate that platinum-bound 17864 still exerts its multikinase inhibitor effects and that linkage of 17864 to ULS or ULS-lysozyme even resulted in a stronger inhibitory effect of the kinase inhibitor.

\section{In vitro cytotoxicity}

As shown in Figure 4, the non-cell-specific multitargeted kinase inhibitor sunitinib malate reduced the cell viability of HK-2 cells in a dose-dependent manner with an $\mathrm{IC}_{50}$ of $12 \mu \mathrm{M}$. In contrast, exposure of HK-2 cells to equimolar amounts of 17864-ULS-lysozyme did not result in decreased cell viability. The absence of cytotoxic effects observed for 17864-ULS-lysozyme is in agreement with previous studies performed with another renal-specific conjugate, ie, SB202190-ULS-lysozyme, directed against a different profibrotic kinase. ${ }^{25}$ As anticipated, methionine-modified lysozyme alone was also non-toxic to HK-2 cells (data not shown).

\section{Pharmacokinetic studies}

Figure 5 shows the plasma disappearance curves of 17864ULS-lysozyme and sunitinib after a single intravenous injection of the compounds in mice. Pharmacokinetic parameters were calculated by fitting the data to a two-compartment model (Table 1). When comparing the plasma data of 17864ULS-lysozyme and sunitinib, the most pronounced differences 
A

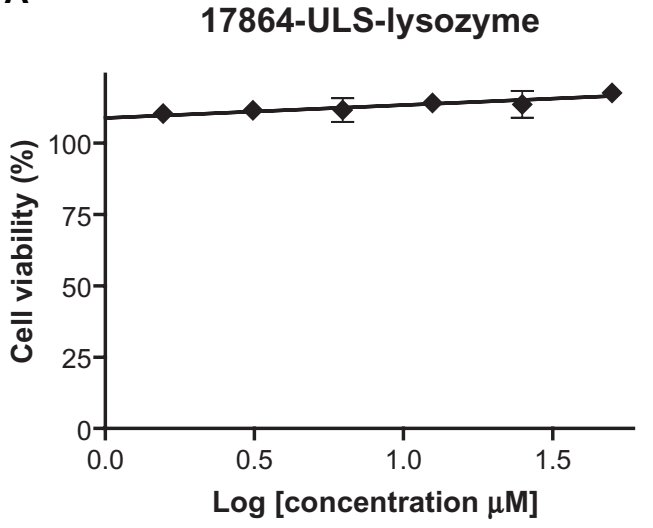

B

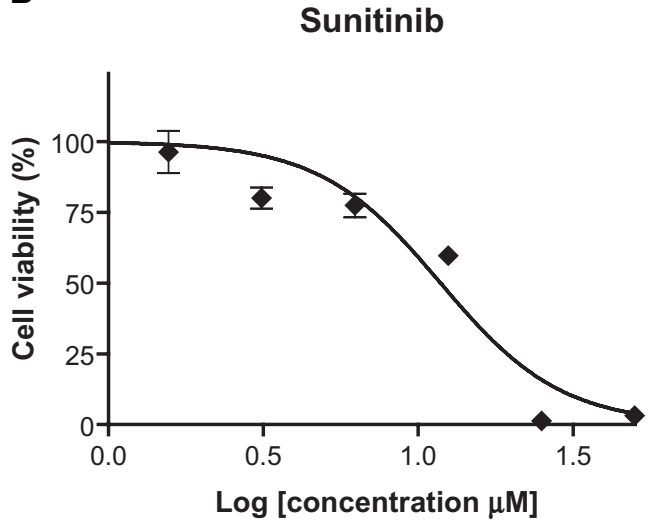

Figure 4 Cell viability of HK-2 cells exposed to $0-50 \mu \mathrm{M}$ I7864-ULS-lysozyme (Panel A) or sunitinib malate (Panel B). Untreated HK-2 cells were used as control and set at $100 \%$.

Note: Data represent the mean $(n=6) \pm$ standard deviation.

were observed in the distribution volumes of the compounds. The initial distribution volume $\left(\mathrm{V}_{1}\right)$ of sunitinib was over 15-fold higher than for 17864-ULS-lysozyme, which reflects the different capability of a small-molecule drug versus a hydrophilic macromolecular conjugate to penetrate into cells and tissues, as well as the binding of free sunitinib to proteins in plasma and tissues. ${ }^{10}$ Distribution of 17864-ULS-lysozyme will be restricted to the circulation and the extracellular fluids, as it cannot passively diffuse across membranes. The plasma elimination rate of 17864-ULS-lysozyme is in agreement with results obtained in earlier studies with other kinase inhibitorULS-lysozyme conjugates. ${ }^{23-25}$ Furthermore, no free 17864 could be detected in the circulation after administration of 17864-ULS-lysozyme, confirming the stability of this type of drug-protein conjugate.

Internalization of 17864-ULS-lysozyme into proximal tubular cells of the kidneys was demonstrated by immunohistochemical staining of the lysozyme part of the conjugate and double staining of the internalizing megalin receptor on the apical membrane of proximal tubular cells (Figure 6A). Uptake of 17864-ULS-lysozyme into the proximal tubular cells was observed within 10 minutes after intravenous administration. The observation that internalized 17864-ULS-lysozyme was localized in close proximity of the megalin receptor indicates that the internalization was still ongoing at this time point. At 1 hour and 4 hours after administration, further processing of 17864-ULS-lysozyme in perinuclear vesicles was observed, with less intense staining of the conjugate at the luminal brush border. Lastly, at 24 hours postinjection, the accumulated 17864-ULS-lyszoyme was intracellularly degraded, as could be observed from the disappearance of the carrier protein in the immunostained sections. These data are in line with results obtained in earlier studies with a similarly prepared imatinib-ULS-lysozyme conjugate..$^{40}$

We also analyzed the renal drug levels after intravenous injection of 17864-ULS-lysozyme and sunitinib
A

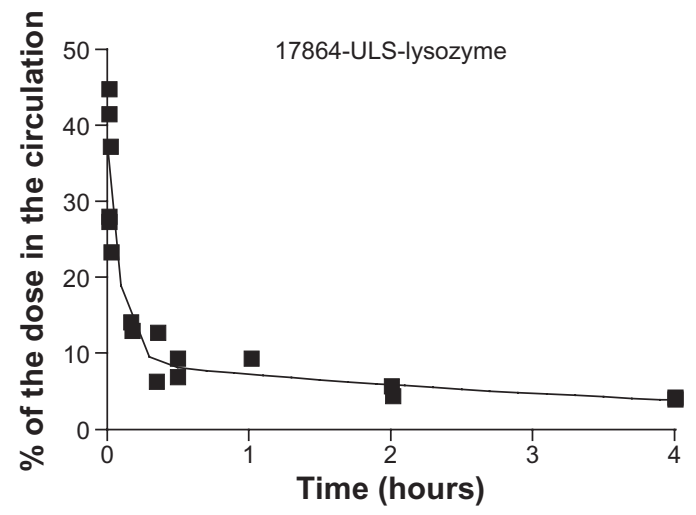

B

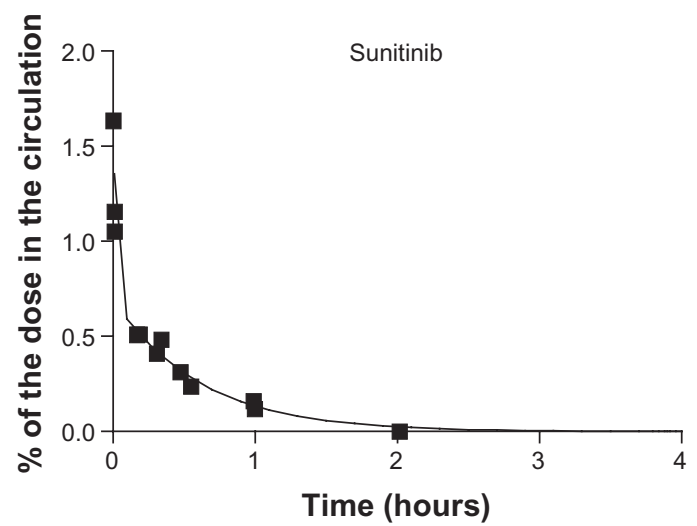

Figure 5 Plasma disappearance curves of I7864-ULS-lysozyme (A) and sunitinib (B) after a single intravenous injection in mice. Plasma concentrations were expressed as the percentage of the dose in the total circulation. The continuous lines represent the data fitted to a nonlinear multi-compartment model. 
Table I Pharmacokinetic parameters of I7864-ULS-lysozyme and sunitinib derived from the plasma disappearance curves after a single intravenous injection

\begin{tabular}{lll}
\hline Pharmacokinetic parameter & $\begin{array}{l}\text { I 7864-ULS- } \\
\text { lysozyme }\end{array}$ & Sunitinib \\
\hline Initial distribution volume $\left(\mathrm{V}_{1}\right)$ & $2.5 \mathrm{~mL}$ & $44 \mathrm{~mL}$ \\
Peripheral distribution volume $\left(\mathrm{V}_{2}\right)$ & $7.3 \mathrm{~mL}$ & $87 \mathrm{~mL}$ \\
Initial half-life $\left(\mathrm{t}_{1 / 2}\right)_{\alpha}$ & 4 minutes & 0.5 minutes \\
Terminal half-life $\left(\mathrm{t}_{1 / 2}\right)_{\beta}$ & 3.3 hours & 25 minutes \\
\hline
\end{tabular}

malate (Figure 6B). Data were fitted with a nonlinear two-compartment model and the pharmacokinetic parameters of the renal data are summarized in Table 2. Both 17864-ULS-lysozyme and sunitinib were rapidly taken up in the kidneys with short absorption half-lives. Maximum renal levels of $6.3 \%$ and $4.9 \%$ of the injected dose were reached within 30 minutes after administration of 17864-ULS-lysozyme and sunitinib, respectively. Comparing the renal residence time of 17864-ULS-lysozyme with the renal residence time of sunitinib, the renally targeted conjugate showed a drastically prolonged renal retention. The renal elimination half-life of sunitinib was 66 minutes, while 17864-ULS-lysozyme provided renal drug levels that lasted for several days and decayed with an elimination half-life of 28 hours. Renal levels of 17864 were still detectable at the end of the experimental period, ie, 3 days after administration of the conjugate. As reflected in the renal AUC of the compounds, the renal drug exposure was increased 28 -fold after administration of 17864-ULS-lysozyme (261\% dose*h versus $9.4 \%$ dose*h for 17864-ULS-lysozyme versus sunitinib, respectively). Figure $6 \mathrm{C}$ shows that more than $95 \%$ of the multitargeted kinase inhibitor 17864 detected in the kidneys was present in the more active ULS-bound form.

The observations that sunitinib was rapidly eliminated from the kidneys can be explained by the presence of efflux transporters on the proximal tubular cell membranes. Sunitinib is a substrate of the broad spectrum efflux transporters P-glycoprotein (P-gp) and ATP-binding cassette subfamily $\mathrm{G}$ member $2 \mathrm{ABCG} 2$, both expressed on the apical membrane of the proximal tubular cells. ${ }^{41,42}$ It is reasonable to assume that slightly modified derivatives of sunitinib, such as 17864, also are substrates of these transporters, while the structural features of the platinum adduct make 17864-ULS a poor substrate for these efflux transporters. The sustained intracellular retention of 17864-ULS may, however, also be explained by other differences between the administered compounds. Firstly, the platinum group of 17864-ULS is charged and the platinum complex will thus have a low tendency to diffuse across membranes. Lastly, another feature that may be involved is the capability of 17864-ULS to bind to intracellular proteins or macromolecules, and such platinum adducts will not easily be excreted into the urine or into the renal interstitium.

\section{Antifibrotic activity of sunitinib and I7864-ULS-lysozyme in renal fibrosis} Inhibitory effects on the activation of PDGFR- $\beta$

Antifibrotic effects of the multikinase inhibitors were studied in mice with UUO-induced tubulointerstitial fibrosis. ${ }^{43}$ We used mice that had suffered from 3 days' ureteral obstruction, ie, the early stages of renal fibrosis. The kidneys of these animals showed all the signs of early fibrosis as indicated by the mild increase in PDGFR- $\beta$ activation and increased deposition and production of profibrotic factors involved in inflammation, EMT and ECM. The activity of 17864-ULS-lysozyme was compared with the inhibitory effects obtained with a low dosage (ie, a single dose equimolar to the conjugate) and a therapeutic dosage (ie, $50 \mathrm{mg} / \mathrm{kg}$ daily) of sunitinib malate. The therapeutic dosage was based on the normal dosage used in cancer treatment and was comparable with the dosage used for the investigation of the antifibrotic effects of sunitinib malate in the treatment of liver cirrhosis (ie, $40 \mathrm{mg} / \mathrm{kg}$ daily). ${ }^{17,44}$ Internalization of 17864-ULS-lysozyme by the renal proximal tubular cells is only possible when the conjugate is able to reach the megalin receptor on the apical membrane of the cells. In this model for tubulointerstitial fibrosis, the urinary flow of the diseased kidney was disturbed, which negatively influenced the renal accumulation of 17864-ULS-lysozyme. Therefore, the intravenous injections of 17864-ULS-lysozyme, low dose sunitinib malate, and the first intraperitoneal injection of the high dose sunitinib malate were administered 1 hour prior to induction of UUO. The second and third intraperitoneal injections of $50 \mathrm{mg} / \mathrm{kg}$ sunitinib malate were administered at 24 hours and 48 hours after UUO-induction, respectively.

In the group treated with the therapeutic dosage of sunitinib, three mice had to be withdrawn from the experiment after the second intraperitoneal injection (day 2), due to drugrelated systemic toxicity. No adverse events were observed in the other groups.

As a first readout of the fibrotic responses in the kidney after ureteral obstruction, we investigated the levels of 
A
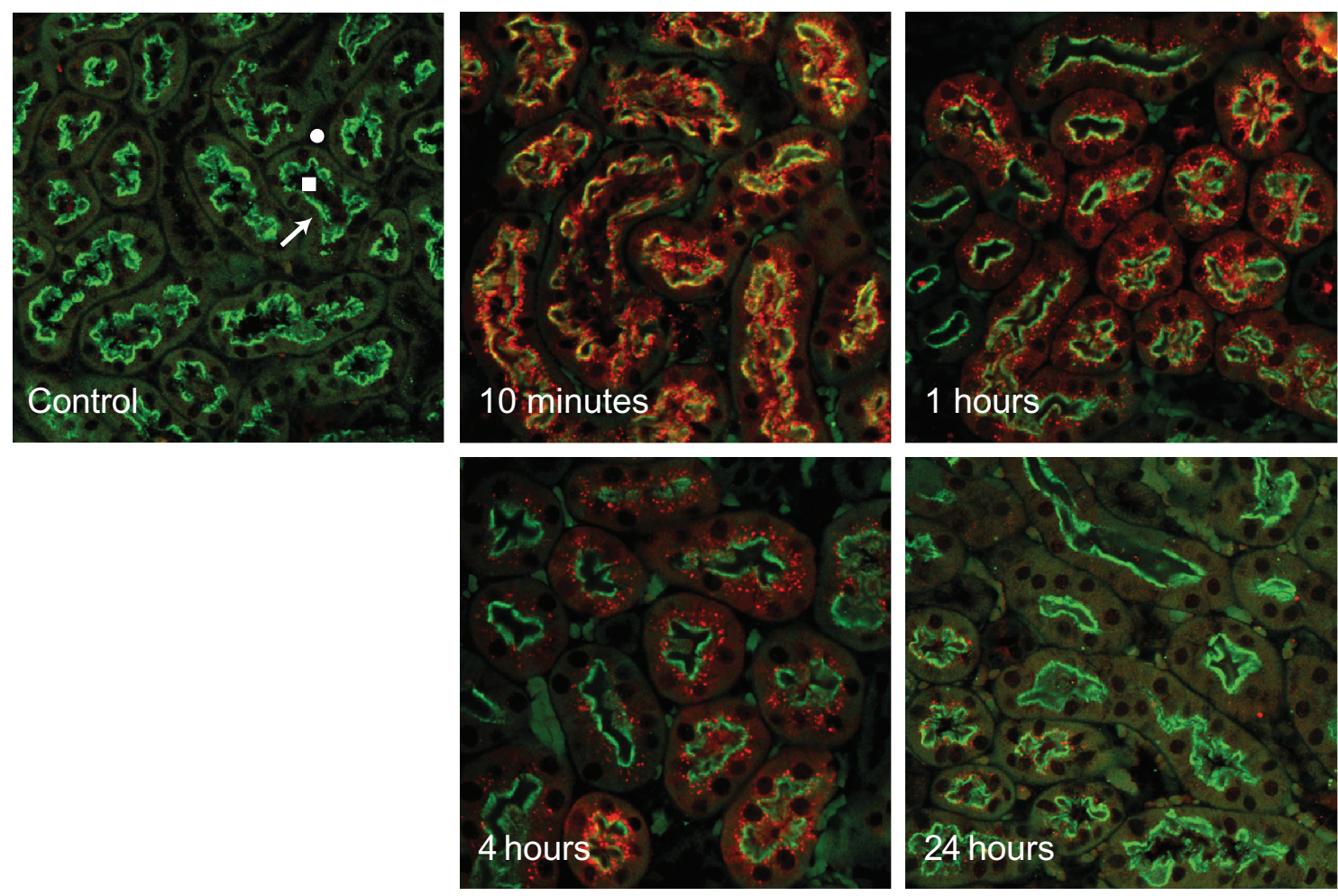

B

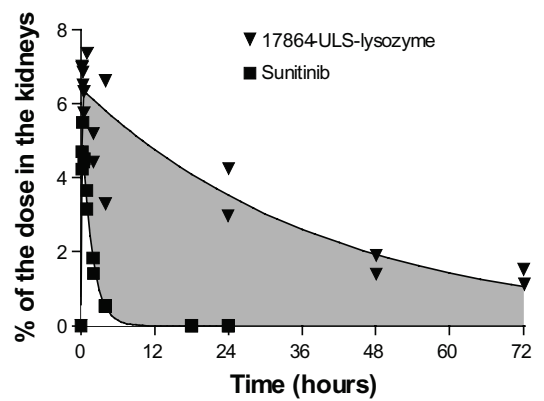

C

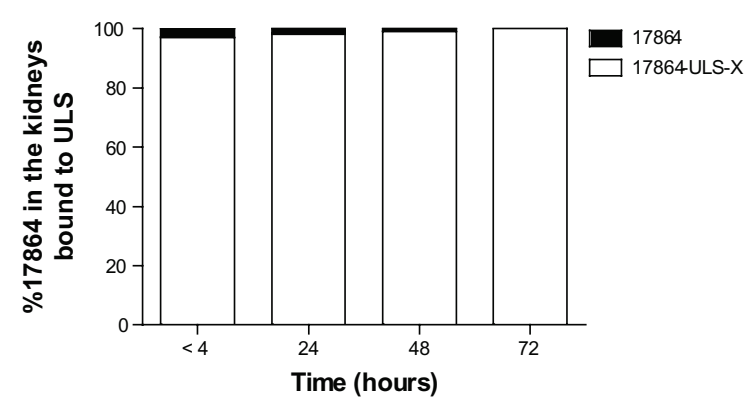

Figure 6 (A) Colocalization of I7864-ULS-lysozyme (anti-LZM staining, red color) and the proximal tubular cell-specific internalizing megalin receptor (green color) at 10 minutes and I, 4, and 24 hours after intravenous administration of a single dose of $20 \mathrm{mg} / \mathrm{kg}$ I7864-ULS-lysozyme. An untreated mouse has been used as control. Symbols in the figure represent the tubular lumen (square), the tubulointerstitial space (circle), and the intracellular compartment of the proximal tubular cells (arrow). (B) Comparison of total renal 17864 levels after a single intravenous injection of I7864-ULS-lysozyme and renal sunitinib levels after a single intravenous injection of sunitinib malate. The increase in AUC obtained with 17864-ULS-lysozyme is highlighted in gray. The continuous lines represent the data fitted to a nonlinear two-compartment model. (C) Percentage of the total renal 17864 levels present in the more active 17864-ULS-X form. The average was taken of the mice sacrificed between 0 and 4 hours and sacrificed at 24,48 , and 72 hours, respectively.

Table 2 Pharmacokinetic parameters of I7864-ULS-lysozyme and sunitinib derived from the renal accumulation curves after a single intravenous injection

\begin{tabular}{lll}
\hline $\begin{array}{l}\text { Pharmacokinetic } \\
\text { parameter }\end{array}$ & $\mathbf{I 7 8 6 4 - U L S - l y s o z y m e}$ & Sunitinib \\
\hline$\left(\mathrm{t}_{1 / 2}\right)_{\text {absorption }}$ & 3 minutes & 4 minutes \\
$\left(\mathrm{t}_{1 / 2}\right)_{\text {elimination }}$ & 28 hours & 66 minutes \\
$\mathrm{C}_{\max }(\%$ of the dose $)$ & $6.3 \%$ & $4.9 \%$ \\
$\mathrm{AUC}_{0-\infty}$ & $261 \%$ dose*hours & $9.4 \%$ dose*hours \\
\hline
\end{tabular}

Abbreviations: $t_{1 / 2}$, half-life; $C_{\max }$, maximal concentration; $A U C$, area under the curve. activated PDGFR- $\beta$ tyrosine kinase. Western blot analysis of the p-PDGFR- $\beta$ levels in the renal cortex demonstrated a mild increase in the activation of PDGFR- $\beta$ after 3 days of ureteral obstruction (Figure 7A). Daily treatment with high-dose sunitinib resulted in decreased p-PDGFR- $\beta$ levels in the renal cortex, as compared with the non-treated mice with UUO-induced renal fibrosis. However, no inhibitory effects were observed for 17864-ULS-lysozyme and the low dose sunitinib (Figure 7B). 
A

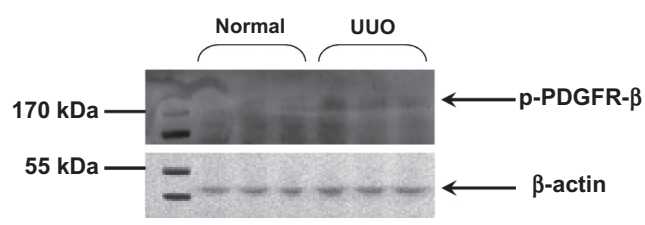

B

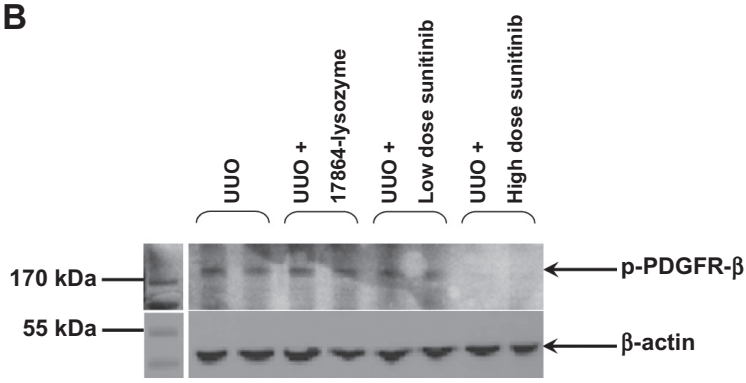

Figure 7 Western blot analysis of activated PDGFR- $\beta$ (p-PDGFR- $\beta$ ) levels in the renal cortex. (A) Three days ureteral obstruction resulted in an increased activation of PDGFR- $\beta$ tyrosine kinase. (B) Inhibitory effects were only obtained with daily intraperitoneal injections of $50 \mathrm{mg} / \mathrm{kg}$ sunitinib malate. Abbreviations: PDGFR, platelet-derived growth factor receptors; UUO, unilateral ureteral obstruction.

\section{Inhibitory effects on downstream profibrotic factors}

As a more downstream readout of profibrotic responses, we evaluated the renal mRNA expression levels of collagen 1A2, PAI-1, and fibronectin (involved in ECM production) and MCP-1 (involved in inflammatory response) in the kidneys. Earlier experiments in animals with UUO-induced tubulointerstitial fibrosis have demonstrated the upregulation of these factors in this animal model. ${ }^{24,45,46}$ Indeed, the mRNA expression levels of collagen 1A2, PAI-1, fibronectin, and MCP-1 in the kidneys were significantly elevated in mice with 3 days' UUO compared with normal mice (Figure S1). No inhibitory effects on the elevated mRNA expression levels of the profibrotic genes, however, were obtained with 17864-ULSlysozyme and the low-dose sunitinib. Mice with UUO-induced tubulointerstitial fibrosis treated with a daily intraperitoneal injection of high-dose sunitinib had significantly lower renal mRNA levels of collagen 1A2 and fibronectin. Renal mRNA expression levels were also investigated in renal cortex homogenate, in addition to their analysis in total renal homogenate. These analyses provided similar trends in renal expression of the investigated genes (data not shown).

Renal deposition of $\alpha$-SMA, collagen IV, and vimentin in paraffin-embedded kidney sections was investigated by immunostaining (Figure S2). Daily treatment with $50 \mathrm{mg} / \mathrm{kg}$ sunitinib malate decreased the deposition of vimentin in the kidneys, although these differences were not significant when quantified by morphometric analysis. Treatment with 17864-ULS-lysozyme and low-dose sunitinib did not affect the elevated expression levels observed after ureter obstruction.

Daily treatment with a high dose of sunitinib resulted in a reduction of some of the studied markers, indicating that this multitargeted kinase inhibitor may be beneficial for the treatment of renal fibrosis. The drug-related toxicity observed in this group, however, underscores the need for a more focused delivery of the drug to diseased tissues, as undertaken in this study. As anticipated, the single low sunitinib dose showed no therapeutic benefit. Our pharmacokinetic study showed that sunitinib was almost completely eliminated from the kidneys within 12 hours after administration, which explains the lack of efficacy at 3 days after administration. The absence of therapeutic responses following 17864-ULSlysozyme treatment were, however, less expected since active 17864-ULS metabolites could still be detected in the kidneys 3 days after injection. We recently demonstrated the capability of 17864-ULS-lysozyme and its metabolites to inhibit PDGFR- $\beta$ kinase. ${ }^{32}$ There may be several explanations for the observed lack of efficacy of 17864-ULS-lysozyme. First, the inhibitor levels reached within the target cells may have been too low. Treatment with a higher dose or repeated doses of 17864-ULS-lysozyme may overcome this problem. The dose used in the current study (ie, $40 \mathrm{mg} / \mathrm{kg} / \mathrm{dose}$ ) was chosen based on the maximum solubility and injection volume of the conjugate that can be tolerated by mice after intravenous injection without overloading the systemic circulation. Furthermore, the treatment of mice in this model with 17864-ULS-lysozyme was limited to a single dose, since the obstruction of the ureter prevents the necessary transport of the conjugate to the apical side of the proximal tubular cells. One of the possibilities to overcome this problem would be to investigate the efficacy of 17864-ULS-lysozyme in a UUO model in which the obstruction is reversed after inducing renal fibrosis. It has however been reported that restoration of the ureter can be cumbersome due to adhesions of the tissue around the ligature; the inner walls of the ureter can stay attached to each other thereby preventing the necessary recovery of the urinary flow. This can be improved by clamping the ureter and subsequently replacing the clip every 2 days to prevent the inner walls of the ureter from merging, ${ }^{47}$ or by using an alternative strategy in which the obstructed ureter is replaced by the contralateral (healthy) kidney. ${ }^{48}$ 
Currently, both methods to reverse the ureter obstruction are still in the developmental stage and further validation is needed to obtain a reproducible model, representative of tubulointerstitial fibrosis in human. As an alternative to the UUO model, renal disease models like the unilateral renal ischemia-reperfusion ( $\mathrm{I} / \mathrm{R}$ ) mode $\mathrm{l}^{25}$ and diabetic nephropathy model ${ }^{49}$ can be used for studying the efficacy of 17864-ULSlysozyme in tubulointerstitial fibrosis. Such models will also permit repeated administration of the conjugate, since urine flow and proximal tubular reabsorption are not blocked by ureter ligation, and have been used by us for testing of renally targeted conjugates. ${ }^{23,25}$ It is advisable, however, to demonstrate the therapeutic efficacy of sunitinib in these alternative animal models before testing the renally targeted conjugate. The potential activity of multikinase inhibitors and the required intrarenal dose level is not known at present and needs to be investigated prior to efficacy evaluation of renally targeted conjugates, similar to the current study using the UUO model.

Besides underdosing, several other explanations may be given for the lack of efficacy of 17864-ULS-lysozyme in the present study. 17864-ULS may not escape easily from the lysosomal compartment, where 17864-ULS-lysozyme accumulates upon megalin-mediated endocytosis. When the charged 17864-ULS metabolites cannot diffuse readily over membranes, as discussed above, only free 17864 can reach the cytosolic kinases or membrane-bound receptor tyrosine kinases. Another explanation for the lack of in vivo efficacy may be that high-dose sunitinib exerts its antifibrotic activity via other cell types besides proximal tubular cells to counteract fibrosis. Although the proximal tubular cells play a pivotal role in the pathogenesis of tubulointerstitial fibrosis, peritubular endothelial cells and interstitial fibroblasts are also involved. ${ }^{1}$ Despite the prolonged retention of 17864 ULS in the kidneys, these cell types will be avoided by the drug-lysozyme conjugate. Further investigations in which we study the activity of 17864-ULS-lysozyme within the kidney after multiple dosing are therefore needed.

\section{Conclusions}

In the present study, we investigated the potential use of the multikinase inhibitor sunitinib as an antifibrotic agent in renal fibrosis. To enhance renal accumulation and hence increase the renal selectivity and lower its toxicity, a derivative of the multitargeted kinase inhibitor sunitinib was developed, ie, 17864. This derivative was conjugated to the renal carrier protein lysozyme via the platinum linker ULS. The resulting 17864-ULS-lysozyme conjugate and its
17864-ULS metabolites were active in a multikinase assay. Upon systemic administration in mice, 17864-ULS-lysozyme provided sustained levels of ULS-bound 17864 in the kidneys. We will evaluate the potential antifibrotic effects of this type of renally targeted multikinase inhibitor conjugates in models of renal fibrosis that will allow frequent dosing of the conjugate, in order to provide intrarenal levels of a platinum-bound sunitinib analog without the systemic side effects of non-cell specific multikinase inhibitors.

\section{Acknowledgments}

We would like to thank KMA van Dorenmalen for her assistance in the animal experiments. We also would like to thank DM van der Giezen for her assistance in the animal efficacy study and immunohistochemical analyses. This work was made possible by a grant from the European Framework program FP6 (LSHB-CT-2007-036644).

\section{Disclosure}

The authors report no conflicts of interest in this work.

\section{References}

1. Zeisberg M, Neilson EG. Mechanisms of tubulointerstitial fibrosis. J Am Soc Nephrol. 2010;21(11):1819-1834.

2. Boor P, Ostendorf T, Floege J. Renal fibrosis: novel insights into mechanisms and therapeutic targets. Nat Rev Nephrol. 2010;6(11):643-656.

3. Mezzano SA, Droguett MA, Burgos ME, et al. Overexpression of chemokines, fibrogenic cytokines, and myofibroblasts in human membranous nephropathy. Kidney Int. 2000;57(1):147-158.

4. Sean Eardley K, Cockwell P. Macrophages and progressive tubulointerstitial disease. Kidney Int. 2005;68(2):437-455.

5. Hewitson TD. Renal tubulointerstitial fibrosis: common but never simple. Am J Physiol Renal Physiol. 2009;296(6):F1239-F1244.

6. Dolman ME, Harmsen S, Storm G, Hennink WE, Kok RJ. Drug targeting to the kidney: Advances in the active targeting of therapeutics to proximal tubular cells. Adv Drug Deliv Rev. 2010;62(14): 1344-1357.

7. Ripley E. Complementary effects of angiotensin-converting enzyme inhibitors and angiotensin receptor blockers in slowing the progression of chronic kidney disease. Am Heart J. 2009;157(6 Suppl):S7-S16.

8. Yu L, Noble NA, Border WA. Therapeutic strategies to halt renal fibrosis. Curr Opin Pharmacol. 2002;2(2):177-181.

9. Kontovinis LF, Papazisis KT, Touplikioti P, Andreadis C, Mouratidou D, Kortsaris AH. Sunitinib treatment for patients with clear-cell metastatic renal cell carcinoma: clinical outcomes and plasma angiogenesis markers. BMC Cancer. 2009;9:82

10. Sablin MP, Dreyer C, Colichi C, et al. Benefits from pharmacological and pharmacokinetic properties of sunitinib for clinical development. Expert Opin Drug Metab Toxicol. 2010;6(8):1005-1015.

11. Lee WJ, Lee JL, Chang SE, et al. Cutaneous adverse effects in patients treated with the multitargeted kinase inhibitors sorafenib and sunitinib. Br J Dermatol. 2009;161(5):1045-1051.

12. Karaman MW, Herrgard S, Treiber DK, et al. A quantitative analysis of kinase inhibitor selectivity. Nat Biotechnol. 2008;26(1):127-132.

13. Bonner JC. Regulation of PDGF and its receptors in fibrotic diseases. Cytokine Growth Factor Rev. 2004;15(4):255-273.

14. Trojanowska M. Role of PDGF in fibrotic diseases and systemic sclerosis. Rheumatology (Oxford). 2008;47 Suppl 5:v2-v4. 
15. Kanellis J, Paizis K, Cox AJ, et al. Renal ischemia-reperfusion increases endothelial VEGFR-2 without increasing VEGF or VEGFR-1 expression. Kidney Int. 2002;61(5):1696-1706.

16. Malmstrom NK, Kallio EA, Rintala JM, et al. Vascular endothelial growth factor in chronic rat allograft nephropathy. Transpl Immunol. 2008;19(2):136-144.

17. Tugues S, Fernandez-Varo G, Munoz-Luque J, et al. Antiangiogenic treatment with sunitinib ameliorates inflammatory infiltrate, fibrosis, and portal pressure in cirrhotic rats. Hepatology. 2007;46(6):1919-1926.

18. Force T, Krause DS, Van Etten RA. Molecular mechanisms of cardiotoxicity of tyrosine kinase inhibition. Nat Rev Cancer. 2007;7(5): 332-344.

19. Bovelli D, Plataniotis G, Roila F. Cardiotoxicity of chemotherapeutic agents and radiotherapy-related heart disease: ESMO Clinical Practice Guidelines. Ann Oncol. 2010;21 Suppl 5:v277-v282.

20. Di Lorenzo G, Autorino R, Bruni G, et al. Cardiovascular toxicity following sunitinib therapy in metastatic renal cell carcinoma: a multicenter analysis. Ann Oncol. 2009;20(9):1535-1542.

21. Bhojani N, Jeldres C, Patard JJ, et al. Toxicities associated with the administration of sorafenib, sunitinib, and temsirolimus and their management in patients with metastatic renal cell carcinoma. Eur Urol. 2008;53(5):917-930.

22. Rosenbaum SE, Wu S, Newman MA, West DP, Kuzel T, Lacouture ME. Dermatological reactions to the multitargeted tyrosine kinase inhibitor sunitinib. Support Care Cancer. 2008;16(6):557-566.

23. Prakash J, de Borst MH, Lacombe M, et al. Inhibition of renal rho kinase attenuates ischemia/reperfusion-induced injury. $J$ Am Soc Nephrol. 2008;19(11):2086-2097.

24. Prakash J, de Borst MH, van Loenen-Weemaes AM, et al. Cell-specific delivery of a transforming growth factor-beta type I receptor kinase inhibitor to proximal tubular cells for the treatment of renal fibrosis. Pharm Res. 2008;25(10):2427-2439.

25. Prakash J, Sandovici M, Saluja V, et al. Intracellular delivery of the p38 mitogen-activated protein kinase inhibitor SB202190 [4-(4fluorophenyl)-2-(4-hydroxyphenyl)-5-(4-pyridyl)1H-imidazole] in renal tubular cells: a novel strategy to treat renal fibrosis. $J$ Pharmacol Exp Ther. 2006;319(1):8-19.

26. Christensen EI, Verroust PJ, Nielsen R. Receptor-mediated endocytosis in renal proximal tubule. Pflugers Arch. 2009;458(6):1039-1048.

27. Temming K, Fretz MM, Kok RJ. Organ- and cell-type specific delivery of kinase inhibitors: a novel approach in the development of targeted drugs. Curr Mol Pharmacol. 2008;1(1):1-12.

28. Gonzalo T, Beljaars L, van de Bovenkamp M, et al. Local inhibition of liver fibrosis by specific delivery of a platelet-derived growth factor kinase inhibitor to hepatic stellate cells. J Pharmacol Exp Ther. 2007;321(3):856-865.

29. Liu Y, Gray NS. Rational design of inhibitors that bind to inactive kinase conformations. Nat Chem Biol. 2006;2(7):358-364.

30. Liao JJ. Molecular recognition of protein kinase binding pockets for design of potent and selective kinase inhibitors. J Med Chem. 2007;50(3):409-424.

31. Gajiwala KS, Wu JC, Christensen J, et al. KIT kinase mutants show unique mechanisms of drug resistance to imatinib and sunitinib in gastrointestinal stromal tumor patients. Proc Natl Acad Sci U S A. 2009;106(5):1542-1547.

32. Harmsen S, Dolman MEM, Nemes Z, et al. Development of a cellselective and intrinsically active multikinase inhibitor bioconjugate. Bioconjug Chem. 2011;22(4):540-545.

33. Sun L, Liang C, Shirazian S, et al. Discovery of 5-[5-fluoro-2-oxo1,2-dihydroindol-(3Z)-ylidenemethyl]-2,4-dimethyl-1H-pyrrole-3carboxylic acid (2-diethylaminoethyl)amide, a novel tyrosine kinase inhibitor targeting vascular endothelial and platelet-derived growth factor receptor tyrosine kinase. J Med Chem. 2003;46(7):1116-1119.
34. van Gijlswijk RP, Talman EG, Peekel I, et al. Use of horseradish peroxidase- and fluorescein-modified cisplatin derivatives for simultaneous labeling of nucleic acids and proteins. Clin Chem. 2002;48(8): 1352-1359.

35. Papazisis KT, Geromichalos GD, Dimitriadis KA, Kortsaris AH. Optimization of the sulforhodamine B colorimetric assay. J Immunol Methods. 1997;208(2):151-158.

36. Rippe A, Rippe C, Sward K, Rippe B. Disproportionally low clearance of macromolecules from the plasma to the peritoneal cavity in a mouse model of peritoneal dialysis. Nephrol Dial Transplant. 2007;22(1):88-95.

37. Sparidans RW, Iusuf D, Schinkel AH, Schellens JH, Beijnen JH. Liquid chromatography-tandem mass spectrometric assay for the light sensitive tyrosine kinase inhibitor axitinib in human plasma. J Chromatogr $B$ Analyt Technol Biomed Life Sci. 2009;877(32):4090-4096.

38. Fretz MM, Dolman ME, Lacombe M, et al. Intervention in growth factor activated signaling pathways by renally targeted kinase inhibitors. J Control Release. 2008;132(3):200-207.

39. Temming K, Lacombe M, Schaapveld RQ, et al. Rational design of RGD-albumin conjugates for targeted delivery of the VEGF-R kinase inhibitor PTK787 to angiogenic endothelium. Chem Med Chem. 2006;1(11):1200-1203.

40. Dolman ME, van Dorenmalen KM, Pieters EH, et al. Imatinib-ULSlysozyme: A proximal tubular cell-targeted conjugate of imatinib for the treatment of renal diseases. $J$ Control Release. 2011. [Epub ahead of print.] doi:10.1016/j.jconrel.2011.08.041.

41. Huls M, Brown CD, Windass AS, et al. The breast cancer resistance protein transporter ABCG2 is expressed in the human kidney proximal tubule apical membrane. Kidney Int. 2008;73(2):220-225.

42. Shukla S, Robey RW, Bates SE, Ambudkar SV. Sunitinib (Sutent, SU11248), a small-molecule receptor tyrosine kinase inhibitor, blocks function of the ATP-binding cassette (ABC) transporters P-glycoprotein (ABCB1) and ABCG2. Drug Metab Dispos. 2009;37(2):359-365.

43. Yang H-C, Zuo Y, Fogo AB. Models of chronic kidney disease. Drug Discov Today Dis Models. 2010;7(1-2):13-19.

44. Demetri GD, van Oosterom AT, Garrett CR, et al. Efficacy and safety of sunitinib in patients with advanced gastrointestinal stromal tumour after failure of imatinib: a randomised controlled trial. Lancet. 2006;368(9544):1329-1338.

45. Chung AC, Huang XR, Zhou L, Heuchel R, Lai KN, Lan HY. Disruption of the Smad7 gene promotes renal fibrosis and inflammation in unilateral ureteral obstruction (UUO) in mice. Nephrol Dial Transplant. 2009;24(5):1443-1454.

46. Yuan XP, He XS, Wang CX, Liu LS, Fu Q. Triptolide attenuates renal interstitial fibrosis in rats with unilateral ureteral obstruction. Nephrology (Carlton). 2011;16(2):200-210.

47. Puri TS, Shakaib MI, Chang A, et al. Chronic kidney disease induced in mice by reversible unilateral ureteral obstruction is dependent on genetic background. Am J Physiol Renal Physiol. 2010;298(4): F1024-F1032.

48. Tapmeier TT, Brown KL, Tang Z, Sacks SH, Sheerin NS, Wong W. Reimplantation of the ureter after unilateral ureteral obstruction provides a model that allows functional evaluation. Kidney Int. 2008;73(7): 885-889.

49. Li L, Emmett N, Mann D, Zhao X. Fenofibrate attenuates tubulointerstitial fibrosis and inflammation through suppression of nuclear factor-kappaB and transforming growth factor-beta $1 / \mathrm{Smad} 3$ in diabetic nephropathy. Exp Biol Med (Maywood). 2010;235(3):383-391. 


\section{Supplementary figures}

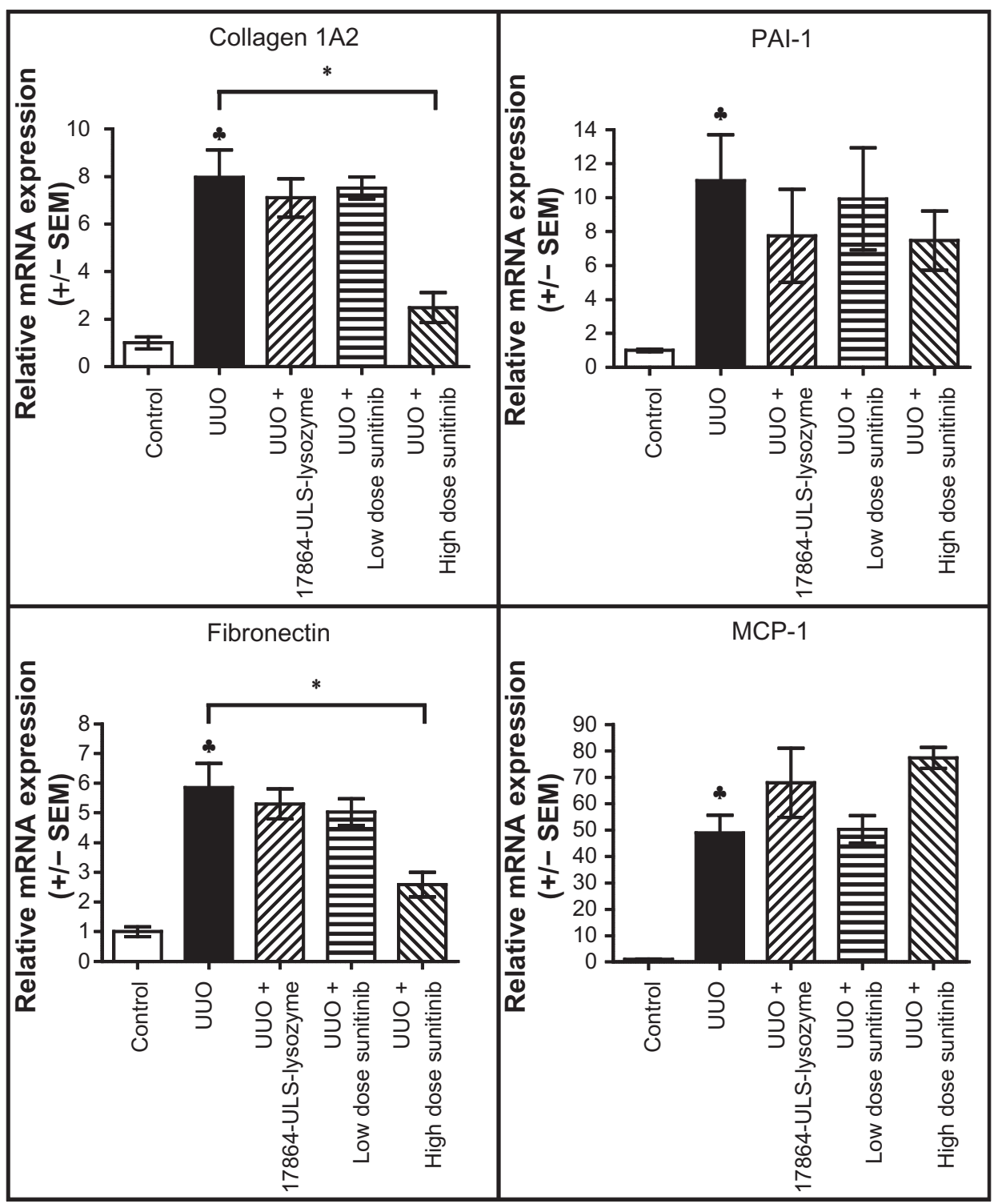

Figure SI mRNA expression of collagen IA2, PAI-I, fibronectin, and MCP-I in the kidneys. The mRNA levels were determined by qRT-PCR and normalized to the household gene TBP. The normalized mRNA expression levels in the kidneys of treated and non-treated mice with UUO were related to the normalized mRNA expression levels in the kidneys of control mice (set at I).

Notes: Data represent the mean $+/-$ SEM. Statistical differences between the non-treated mice with UUO and control mice are indicated as $*(P<0.05)$. Statistical differences between the treated and non-treated mice with UUO are indicated as $*(P<0.05)$.

Abbreviations: UUO, unilateral ureteral obstruction; qRT-PCR, quantitative reverse transcription polymerase chain reaction; SEM, standard error of the mean. 


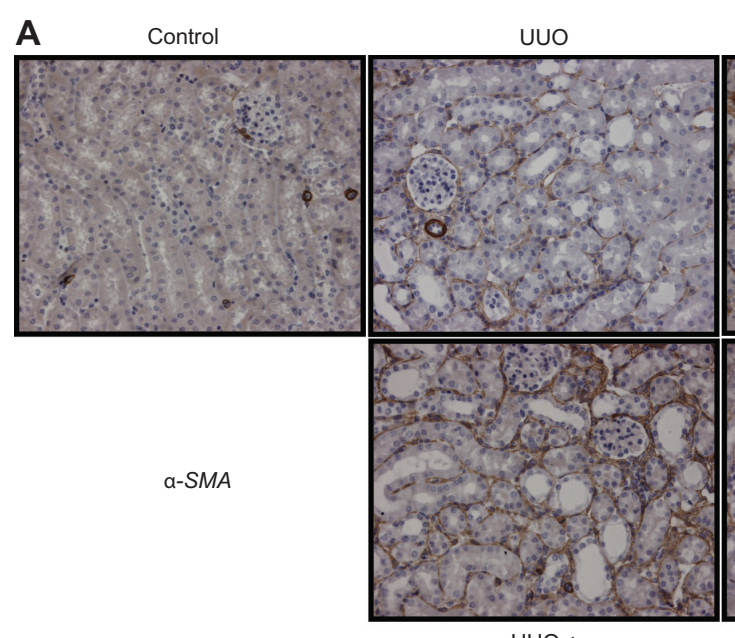

UUO +

Low dose sunitinib
UUO +

17864-ULS-lysozyme

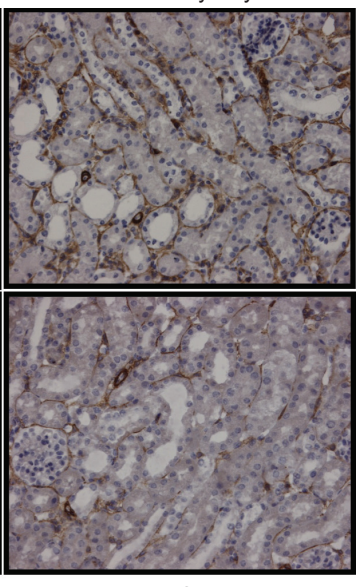

UUO +

High dose sunitinib

UUO +

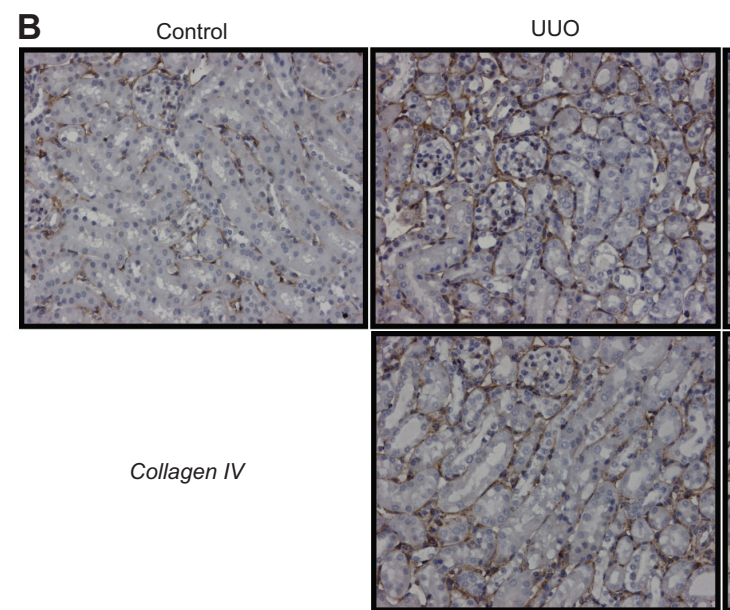

Collagen IV

UUO +

Low dose sunitinib

17864-ULS-Iysozyme

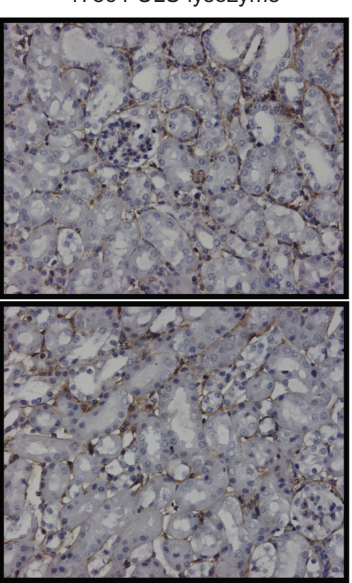

UUO +

High dose sunitinib

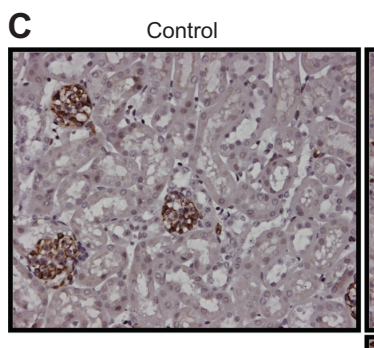

Vimentin

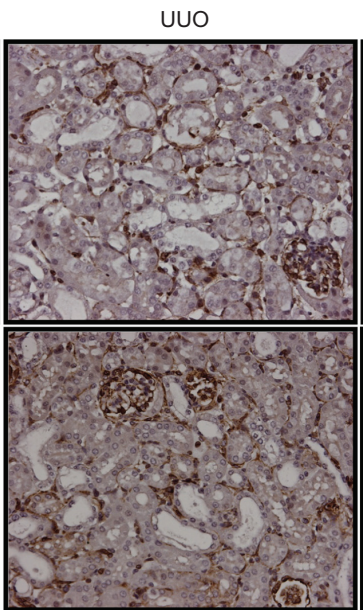

$\mathrm{UUO}+$

Low dose sunitinib

UUO +

17864-ULS-lysozyme

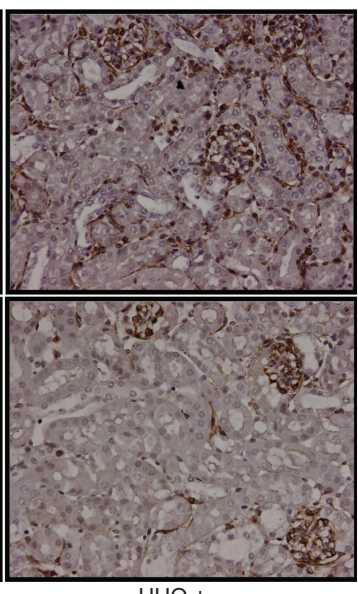

gh dose sunitinib

Figure S2 Representative microscopic images of paraffin-embedded kidney sections immunostained for $\alpha$-SMA (A), collagen IV (B), and vimentin (C). In the pathogenesis of renal fibrosis $\alpha$-SMA is involved in EMT of normal epithelial cells into myofibroblasts, collagen IV in ECM production and vimentin in both processes.

Note: The magnification for all images was 20x.

Abbreviations: SMA, smooth muscle actin; EMT, epithelial-to-mesenchymal transition; ECM, extracellular matrix; UUO, unilateral ureteral obstruction. 
International Journal of Nanomedicine

Dovepress

\section{Publish your work in this journal}

The International Journal of Nanomedicine is an international, peerreviewed journal focusing on the application of nanotechnology in diagnostics, therapeutics, and drug delivery systems throughou the biomedical field. This journal is indexed on PubMed Central, MedLine, CAS, SciSearch ${ }^{\circledR}$, Current Contents ${ }^{\circledR} /$ Clinical Medicine,
Journal Citation Reports/Science Edition, EMBase, Scopus and the Elsevier Bibliographic databases. The manuscript management system is completely online and includes a very quick and fair peer-review system, which is all easy to use. Visit http://www.dovepress.com/ testimonials.php to read real quotes from published authors.

Submit your manuscript here: http://www.dovepress.com/international-journal-of-nanomedicine-journal 